\title{
594.
}

\section{ON A DIFFERENTIAL EQUATION IN THE THEORY OF ELLIPTIC FUNCTIONS.}

[From the Messenger of Mathematics, vol. Iv. (1875), pp. 69, 70.]

THE following equation presented itself to me in connexion with the cubic transformation :

$$
Q^{2}-Q\left(k+\frac{1}{k}\right)-3=3\left(1-k^{2}\right) \frac{d Q}{d k} .
$$

Writing as usual $k=u^{4}$, I was aware that a solution was

$$
Q=\frac{v^{2}}{u^{2}}+2 u v
$$

where $u, v$ are connected by the modular equation

$$
u^{4}-v^{4}+2 u v\left(1-u^{2} v^{2}\right)=0 ;
$$

but it was no easy matter to verify that the differential equation was satisfied. After a different solution, it occurred to me to obtain the relation between $(Q, u)$; or, what is the same thing, $(Q, k)$, viz. eliminating $v$, we find

$$
Q^{4}-6 Q^{2}-4\left(u^{4}+\frac{1}{u^{4}}\right) Q-3=0,
$$

or say

whence also

$$
\frac{1}{Q}\left(Q^{4}-6 Q^{2}-3\right)=4\left(k+\frac{1}{k}\right)
$$

$$
\frac{1}{Q}\left(Q^{4}-6 Q^{2} \pm 8 Q-3\right)=4\left(k \pm 2+\frac{1}{k}\right)
$$


594] ON A DIFFERENTIAL EQUATION IN THE THEORY OF ELLIPTIC FUNCTIONS. 245 that is,

and

$$
\frac{1}{Q}(Q-1)^{3}(Q+3)=4\left\{\sqrt{ } k+\frac{1}{\sqrt{ } k}\right\}^{2}
$$

and thence

$$
\frac{1}{Q}(Q+1)^{3}(Q-3)=4\left\{\sqrt{ } k-\frac{1}{\sqrt{ } k}\right\}^{2}
$$

$$
\frac{(Q+1)^{3}(Q-3)}{(Q-1)^{3}(Q+3)}=\left(\frac{k-1}{k+1}\right)^{2}
$$

viz. the value of $Q$ thus determined must satisfy the differential equation. This is easily verified, for, in virtue of the assumed integral, we have

$$
Q^{2}-3-\frac{1}{4}\left(Q^{4}-6 Q^{2}-3\right)=3\left(1-k^{2}\right) \frac{d Q}{d k}
$$

that is,

$$
Q^{4}-10 Q^{2}+9=-12\left(1-k^{2}\right) \frac{d Q}{d k}
$$

or finally

$$
\left(Q^{2}-1\right)\left(Q^{2}-9\right)=-12\left(1-k^{2}\right) \frac{d Q}{d k},
$$

an equation which is at once obtained by differentiating logarithmically the former result, and we have thus the verification of the solution. This is, however, a particular integral only; and it appears doubtful whether there exists a general-integral of an algebraical form. 